\title{
NGHIÊN CỨU HIÊU QUẢ KHỬ KHUẨN CỦA DUNG DỊCH SIÊU ÔXY HÓA TRỀN DÂY CHUYỀN CHẾ BIẾN BACCH TUỘC
}

\author{
Nguyễn Văn Hà ${ }^{1,}$, Nguyễn Hoài Châu ${ }^{1}$, Hoàng Văn Tú ${ }^{1}$, Nguyễn Văn Thành ${ }^{1}$, \\ Triệu Thị Mỹ Hạnh² \\ ${ }^{I}$ Viện Công nghệ môi truờng, Viện HLKHCNVN, 18 Hoàng Quốc Việt, Cầu Giấy, Hà Nội \\ ${ }^{2}$ Công ty BASEAFOOD, Bà Rịa, Vũng Tàu \\ *Email:ng_vanha@yahoo.com
}

Đến Tòa soạn: 18/10/2012; Chấp nhận đăng: 27/8/2013

\section{TÓM TẮT}

Hiệu quả khử khuẩn của dung dịch hoạt hóa điện hóa Supowa đã được xác định đối với các vi khuẩn chủng quốc tế E.Coli (ATCC®14169 ${ }^{\mathrm{TM}}$ ), S. aureus (ATCC®25923 ${ }^{\mathrm{TM}}$ ), Salmonella $\left(\mathrm{ATCC}{ }^{\circledR} 25241^{\mathrm{TM}}\right)$ và L.monocytogenes $\left(\mathrm{ATCC}{ }^{\circledR} 7644^{\mathrm{TM}}\right.$ ). Khi có mặt peptone $0,1 \%$, các vi khuẩn trên ở mật độ $10^{8} \mathrm{CFU} / \mathrm{ml}$ bị tiêu diệt hoàn toàn sau 2 phút tiếp xúc với dung dịch Supowa có nồng độ chất ôxy hóa $50 \mathrm{mg} / \mathrm{l}$ (tính tương đương với clo hoạt tính). Khi khử trùng bề mặt bàn inox và rổ nhựa, hiệu quả khử khuẩn của phương pháp sử dụng Supowa tốt hơn nhiều so với phương pháp thường qui $(\mathrm{p}<0,05)$. Trong trường hợp khử trùng bạch tuộc nguyên liệu, Supowa thể hiện hiệu quả khử trùng tốt hơn phương pháp thường qui nhưng chưa rõ rệt ( $\mathrm{p}$ > $0,05)$. Dung dịch Supowa được đề xuất sử dụng làm tác nhân khử trùng thay thế $\mathrm{Ca}(\mathrm{OCl})_{2}$ trong chế biến thủy sản.

Tù khóa: khử trùng thủy sản, chế biến bạch tuộc, hoạt hóa điện hóa, dung dịch Supowa

\section{Mở ĐÀ̀}

Sử dụng các phương pháp vệ sinh khử trùng hiệu quả các bề mặt tiếp xúc và bán thành phẩm trong đây chuyền chế biến đóng vai trò quyết định đảm bảo vệ sinh an toàn thực phẩm trong sản phẩm thủy sản. Bên cạnh các chế phẩm khử trùng truyền thống, trong những năm gần đây dung dịch điện hoạt hóa nước muối loãng (có các tên gọi khác nhau Anolyte, EOW electrolyzed oxidizing water, $\mathrm{AEW}$ - activive electrolyzed water...) đã được nghiên cứu sử dụng làm chế phẩm khử trùng trong chế biến thủy sản do đặc tính hiệu lực diệt khuẩn cao, thân thiện với con người và môi trường của nó. Mukhina $\mathrm{L}$. B. và các đồng nghiệp [1] khẳng định rằng dung dịch này là một chất khử trùng rất hữu hiệu để diệt các loại vi khuẩn Enterobacter cloaceae, Baccillus cereus, Pseudomonas, Staphylococcus aureus trên bề mặt tiếp xúc với sản phẩm trong chế biến thủy sản như gạch men, tấm nhựa, thép không gỉ. Kết quả nghiên cứu của Melekhin D.V và các cộng sự [2] đã cho thấy rửa cá và làm đông lạnh bằng nước đá được điều chế bằng chế phẩm này cho phép gia tăng thời hạn bảo quản các sản phẩm cá lên $30-50 \%$ ở nhiệt độ từ 0 đến $-2{ }^{\circ} \mathrm{C}$. Ozer và Demirci [3] đã tìm ra rằng khi xử lí nguyên liệu và fillet cá hồi 
bằng EOW ở $35^{\circ} \mathrm{C}$ làm giảm được $91,1 \%$ mật độ vi khuẩn $E$. coli $\mathrm{O} 157: \mathrm{H} 7$ và $92,3 \%$ mật độ vi khuẩn $L$. monocytogenes. Huang và các cộng sự $[4,5]$ đã ghi nhận rằng $\mathrm{EOW}$ là một tác nhân làm vệ sinh rất hữu hiệu để làm sạch các bề mặt tiếp xúc với cá ở các kho và chợ cá tới mức có thể tránh được các nhiễm khuẩn thứ cấp. EOW đặc biệt hiệu quả trong việc làm giảm mật độ $E$. coli và $V$. parahaemolyticus bị nhiễm trên sản phẩm cá rô phi. Các tác giả đã ghi nhận rằng cá ngừ được xử lí bằng $\mathrm{EOW}$ kết hợp với khí $\mathrm{CO}$ có thể làm giảm mật độ tổng vi khuẩn tới mức thấp nhất, làm tăng độ tươi ngon của thịt cá ngừ và kéo dài thời gian bảo quản đông lạnh. Các thử nghiệm của tác giả Nguyễn Hoài Châu và công sự đã sử dụng một loại dung dịch điện hoạt hóa có tên là dung dịch Ecachlo để khử trùng dụng cụ nhựa (thớt, rổ), tay công nhân và cá nguyên liệu có so sánh đối chứng với chế phẩm khử trùng đang dùng trong sản xuất là $\mathrm{Ca}(\mathrm{OCl})_{2}$. Các kết quả cho thấy trong $70 \%$ số mẫu, mật độ vi sinh sau khử trùng bằng dung dịch Ecachlo thấp hơn trong mẫu đối chứng khử trùng bằng $\mathrm{Ca}(\mathrm{OCl})_{2}$ với mức độ rõ rệt theo tính toán thống kê $(\mathrm{p}<0,05)$. $30 \%$ số mẫu còn lại, mật độ vi sinh sau khử trùng bằng dung dịch Ecachlo có thấp hơn trong mẫu đối chứng khử trùng bằng $\mathrm{Ca}(\mathrm{OCl})_{2}$ nhưng ở mức độ không phân biệt theo tính toán thống kê $(\mathrm{p}>0,05)$ [6].

Trong các nghiên cứu gần đây, $\mathrm{A}$. Issa-Zacharia và các công sự $[7,8]$ đã so sánh hiệu quả diệt khuẩn của dung dịch $\mathrm{AEW}$ với dung dịch $\mathrm{NaOCl}$ đối với các vi khuẩn cần kiểm soát trong quá trình chế biến thủy sản là E. coli, S. aureus và Salmonella spp ở dạng dịch lỏng tinh khiết. Các kết quả cho thấy, hiệu quả diệt khuẩn của $\mathrm{AEW}$ cao hơn rõ rệt $(\mathrm{p}<0,05)$ so với $\mathrm{NaOCl}$ trong mọi trường hợp. Các tác giả đã đề xuất sử dụng $\mathrm{AEW}$ thay thế $\mathrm{NaOCl}$ để làm tác nhân vệ sinh khử trùng trong công nghiệp chế biến thực phẩm. Sureerat Phuvasate, Yi-Cheng Su [9] đã chứng minh hiệu lực diệt khuẩn cao của EOW đối với các vi khuẩn L. monocytogenes và $M$. morganii và đề xuất rằng cần phải xử lí bề mặt tiếp xúc và các nguyên liệu bằng $\mathrm{EOW}$ để tránh tạo thành màng sinh học trong dây chuyền chế biến thủy sản. S. McCarthy và $\mathrm{W}$. Burkhardt III đã nghiên cứu hiệu quả sử dụng $\mathrm{EOW}$ và đá lạnh $\mathrm{EO}$ để làm giảm mật độ các vi khuẩn hình thành histamine (E. aerogenes, E. cloacae, $K$. pneumoniae, $M$. morganii...) trên bề mặt tiếp xúc thực phẩm và trên da cá. Các kết quả đã cho phép đề xuất sử dụng EOW và đá $E O$ như là một phương tiện hữu hiệu để giảm thiểu sự hình thành histamine trên bề mặt inox và trên da cá trong quá trình xử lí cá nguyên liệu [10].

Bài báo này trình bày một số kết quả nghiên cứu hiệu quả khử trùng của dung dịch siêu ôxy hóa (Supowa) được điều chế bằng công nghệ điện hoạt hóa từ $\mathrm{NaCl}$ đối với các vi khuẩn gây bệnh cần kiểm soát trong quá trình chế biến thủy sản: E. coli, S. aureus, Salmonella và L. monocytogenes. Các kết quả nghiên cứu đã được ứng dụng thử nghiệm để vệ sinh khử trùng bề mặt tiếp xúc (inox và nhựa) và bạch tuộc nguyền liệu trên dây chuyền chế biến thủy sản xuất khẩu.

\section{VẬT LIỆU VÀ PHƯƠNG PHÁP NGHIÊN CỨU}

\subsection{Dung dịch siêu ôxy hóa (Supowa)}

Dung dịch Supowa được điều chế từ $\mathrm{NaCl}$ tinh khiết công nghiệp $(\mathrm{NaCl}>99 \%)$ trên thiết bị điện hoạt hóa SUPOWA sử dụng buồng phản ứng điện hóa MB-11(Nga) do Viện Công nghệ môi trường chế tạo. Dung dịch Supowa sau khi điều chế được sử dụng trong ngày, có nồng độ chất ôxy hóa $500 \pm 20 \mathrm{mg} / \mathrm{l}$ (chuẩn độ bằng phương pháp iôt và tính theo clo hoạt tính), $\mathrm{pH}$ nằm trong khoảng 6,5 - 7,2, nồng độ khoáng (TDS) trong khoảng $900-1100 \mathrm{mg} / \mathrm{l}$ và thế ôxy hóa khử (ORP) trong khoảng $850-950 \mathrm{mV}$ (được đo bằng máy đo đa năng SenSion 156 của hãng $\mathrm{HACH})[11]$. 


\subsection{Phương pháp đánh giá hiệu lụ̣c diệt khuẩn của Supowa}

Các vi khuẩn chủng quốc tế E. coli (ATCC®14169 ${ }^{\mathrm{TM}}$ ), S. aureus (ATCC®25923 ${ }^{\mathrm{TM}}$ ), Salmonella (ATCC ${ }^{\circledR} 25241^{\mathrm{TM}}$ ) và L. monocytogenes (ATCC $\left.{ }^{\circledR} 7644^{\mathrm{TM}}\right)$, ở dạng đông khô KWIKSTIK của Hãng Microbiologics (Mỹ) đã được sử dụng trong các thí nghiệm xác định hiệu lực diệt khuẩn của Supowa. Các vi khuẩn gốc được cấy ria trên môi trường PCA và thu sinh khối vào dung dịch nước muối sinh lí chứa $0,1 \%$ peptone. Dịch vi khuẩn có mật độ $10^{9} \mathrm{cfu} / \mathrm{ml}$ được dùng làm dung dịch ban đầu để xác định hiệu lực diệt khuẩn của các vi khuẩn trên theo thời gian tiếp xúc và nồng độ chất khử khuẩn. Các thí nghiệm xác định nồng độ khử khuẩn được thực hiện với các nồng độ chất ôxy hóa của Supowa từ 0 đến $50 \mathrm{mg} / \mathrm{l}$ trong thời gian 5 phút. Các thí nghiệm xác định thời gian diệt khuẩn được thực hiện với nồng độ chất ôxy hóa của Supowa 50 $\mathrm{mg} / \mathrm{l}$ trong thời gian từ 0 đến 5 phút. Xác định mật độ vi khuẩn sau khi tiếp xúc với Supowa trong dung dịch thí nghiệm bằng phương pháp nuôi cấy và đếm khuẩn lạc trên đĩa thạch đặc hiệu đối với từng vi khuẩn: $E$. coli sử dụng môi trường Chromocult (Merck), S. aureus sử dụng môi trường Baird parker agar (Merck), Salmonella sử dụng môi trường SS agar (Merck) và L.monocytogenes sử dụng môi trường Oxford agar (Merck).

\subsection{Phương pháp đánh giá hiệu quả khử khuẩn của Supowa trên dây chuyền chế biến}

\subsection{1. Đánh giá hiệu quả khử khuẩn của Supowa đối với các bề mặt bàn inox và rổ nhụa}

Chọn ngẫu nhiên 5 bàn thép không rỉ $(120 x 300 \mathrm{~cm})$ dùng chế biến bạch tuộc từ hôm trước đã được vệ sinh qua 2 bước làm sạch chất thải rắn và tráng lại bằng nước sạch. Lấy mẫu bề mặt trước khi khử khuẩn bằng phương pháp tăm bông trên diện tích ô lấy mẫu $50 \mathrm{~cm}^{2}$. Mỗi bàn lấy 2 mẫu ở giữa cách đầu bàn $30 \mathrm{~cm}$. Dùng khăn vải tẩm dung dịch Supowa (nồng độ chất ôxy hóa $100 \mathrm{mg} / \mathrm{l})$ có pha $1 \%$ dung dịch tẩy rửa lau kĩ khắp bề mặt bàn thép không rỉ rồi dội qua nước sạch. Sau đó, dùng khăn tẩm dung dịch Supowa (nồng độ chất ôxy hóa $100 \mathrm{mg} / \mathrm{l}$ ) lau khắp bề mặt bàn. Sau thời gian 5 phút, mặt bàn được tráng nước sạch. Lấy mẫu bề mặt bàn sau khử khuẩn: mỗi bàn 2 mẫu ở giữa cách đầu bàn $50 \mathrm{~cm}$.

Rổ nhựa sau ca sản xuất (10 cái) được vệ sinh làm sạch chất thải rắn và tráng lại bằng nước sạch. Lấy mẫu bề mặt trước khi khử khuẩn bằng phương pháp tăm bông trên diện tích ô lấy mẫu $50 \mathrm{~cm}^{2}$. Nhúng rổ nhựa vào chậu đựng dung dịch Supowa (nồng độ chất ôxy hóa $100 \mathrm{mg} / \mathrm{l}$ ) có pha $1 \%$ dung dịch tẩy rửa và dùng bàn chải cọ khắp lượt rồi tráng qua nước sạch. $\mathrm{Ngâm}$ rổ vào dung dịch Supowa (nồng độ chất ôxy hóa $100 \mathrm{mg} / \mathrm{l}$ ) trong thời gian 5 phút, sau đó lấy mẫu bề mặt sau khử trùng.

Đưa tăm bông đã lấy mẫu vào $10 \mathrm{ml}$ nước muối sinh lí đã tiệt trùng, giữ lạnh mẫu và phân tích vi sinh trong ngày. Các vi khuẩn được nuôi cấy và đếm khuẩn lạc theo phương pháp đổ đĩa trên các môi trường đặc hiệu gồm Tổng vi khuẩn hiếu khí (VKHK), Cloroform, E.coli, $S$. aureus, Salmonella và L.monocytogenes như đã nêu ở mục 2.2. Mật độ vi khuẩn được tính ra số khuẩn lạc trên $1 \mathrm{~cm}^{2}$ diện tích bề mặt dụng cụ $\left(\mathrm{CFU} / \mathrm{cm}^{2}\right)$.

Các mẫu so sánh được lấy theo phương pháp tương tự khi vệ sinh mặt bàn inox và rổ nhựa theo quy trình của nhà máy sử dụng xà phòng $\mathrm{OMO}$ làm chất tẩy rửa và $\mathrm{Ca}(\mathrm{OCl})_{2}$ làm chất khử trùng.

\subsection{2. Đánh giá hiệu quả khử khuẩn của Supowa đối với bạch tuộc nguyên liệu}


Phương pháp khư khuẩn và lấy mẫu phân tích vi sinh: Lấy vào 10 rổ nhựa được đánh số từ 1 đến 10 , mỗi rổ khoảng $10 \mathrm{~kg}$ bạch tuộc nguyên liệu (nguyên con). Lấy ở mỗi rổ 1 mẫu nguyên liệu trước khử trùng (khoảng $0,3 \mathrm{~kg}$ ). Đưa rổ đựng bạch tuộc vào chậu chứa dung dịch Supowa có nồng độ chất ôxy hóa $100 \mathrm{mg} / \mathrm{l}$, dùng tay khuấy đều bạch tuộc trong $60 \mathrm{~s}$. Sau 5 phút, lấy mẫu nguyên liệu sau khử trùng trong mỗi rổ. Các mẫu nguyên liệu được giữ lạnh và chuyển về phòng phân tích vi sinh.

Phân tích vi sinh: Cân mỗi mẫu phân tích đúng $25,0 \mathrm{~g}$ cho vào túi dập mẫu và thêm vào mỗi túi $250 \mathrm{ml}$ nước muối sinh lí đã tiệt trùng. Dập mẫu cho đồng nhất trong vòng 1 phút trên máy chuyên dụng. Phân tích các vi khuẩn Tổng vi khuẩn hiếu khí (môi trường PCA), Coliform và $E$. coli (môi trường Chromocult), S. aureus (môi trường Baird parker agar) bằng phương pháp nuôi cấy và đếm khuẩn lạc trên đĩa thạch. Mật độ vi khuẩn được tính ra số khuẩn lạc trong $1 \mathrm{~g}$ nguyên liệu (CFU/g).

Các mẫu so sánh (20 mẫu trước và sau khử trùng) được lấy theo phương pháp tương tự trên dây chuyền chế biến của nhà máy khi sử dụng chất khử khuẩn là $\mathrm{Ca}(\mathrm{OCl})_{2}$ (nồng độ clo hoạt tính $100 \mathrm{mg} / \mathrm{l})$.

\section{KẾT QUẢ VÀ THẢO LUẬN}

\subsection{Hiệu lực diệt khuẩn của Supowa đối với E.Coli, S. aureus, Salmonella và L.monocytogenes}

Mức độ giảm mật độ vi khuẩn sau thời gian tiếp xúc 5 phút với các nồng độ Supowa khác nhau được biểu diễn trên hình $1 \mathrm{~A}$ và theo thời gian tiếp xúc với Supowa có nồng độ clo hoạt tính $50 \mathrm{mg} / \mathrm{l}$ được nêu trên hình 1B. Trên trục tung biểu diễn mật độ vi khuẩn được tính theo $\log _{10}$.

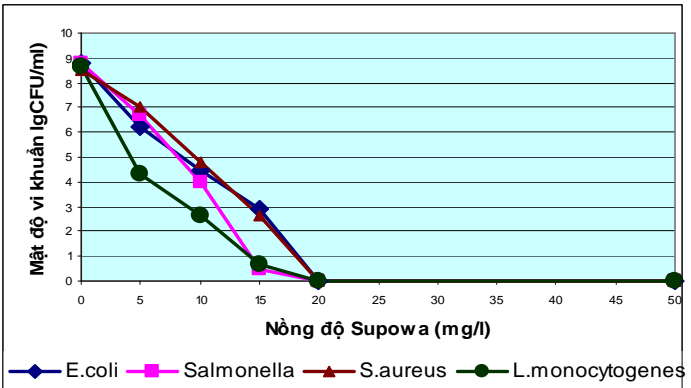

A

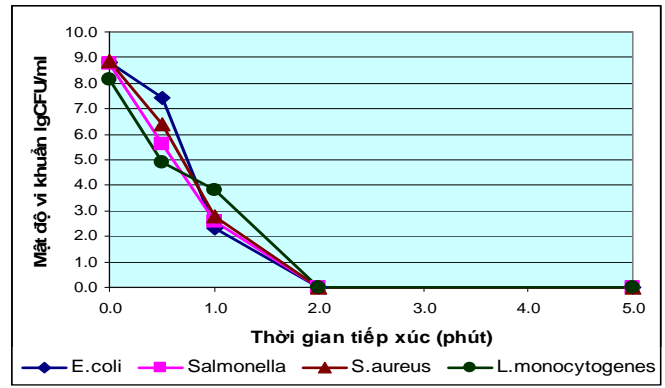

B

Hình 1. Hiệu lực diệt khuẩn theo nồng độ Supowa sau thời gian tiếp xúc 5 phút (A) và thời gian tiếp xúc với Supowa nồng độ $50 \mathrm{mg} / \mathrm{l}(\mathrm{B})$ đối với các vi khuẩn E. coli, S. aureus, Salmonella và L. monocytogenes.

Các kết quả trên cho thấy, mật độ ban đầu của các vi khuẩn $S$. aureus, E. coli, Salmonella, $L$ . monocytogenes là xấp xỉ $10^{8} \mathrm{CFU} / \mathrm{ml}$ đã giảm đến mức không phát hiện được (bị diệt hoàn toàn) trong vòng 5 phút tiếp xúc với Supowa có nồng độ clo hoạt tính bằng và lớn hơn $20 \mathrm{mg} / \mathrm{l}$. Khi cho các dịch chứa vi khuẩn thử nghiệm tiếp xúc với dung dịch Supowa có nồng độ $50 \mathrm{mg} / \mathrm{l}$ thì chỉ sau 2 phút các vi khuẩn trên cũng đều bị tiệu diệt hoàn toàn.

\subsection{Hiệu quả khử khuẩn của Supowa đối với các bề mặt bàn inox và rổ nhựa}


Các kết quả phân tích vi sinh cho thấy bề mặt các bàn inox trước khử trùng đều bị nhiễm khuẩn. Trong đó, $100 \%$ số mẫu (20 mẫu) phát hiện sự có mặt của các vi khuẩn hiếu khí (VKHK), Coliform, S. aureus và Salmonella. Không phát hiện thấy sự có mặt của vi khuẩn E.coli ở tất cả các mẫu và có 3 mẫu $(15 \%)$ có mặt vi khuẩn Listeria. Sau khi khử khuẩn, trong tất cả các mẫu đều không phát hiện thấy các vi khuẩn $S$. aureus, Salmonella và Listeria, nhưng vẫn còn VKHK và Coliform. Điều này cho thấy, cả 2 phương pháp khử trùng đều đã đạt được hiệu quả khử khuẩn khá tốt đối với các vi khuẩn gây bệnh chủ yếu. Hình 2 biểu diễn so sánh hiệu quả khử khuẩn bề mặt bàn inox bằng Supowa và thường qui đối với tổng $\mathrm{VKHK}(\mathrm{A})$ và Coliform (B).

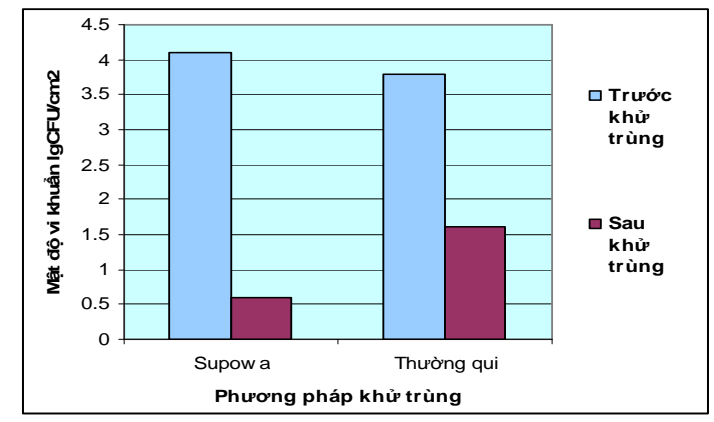

A

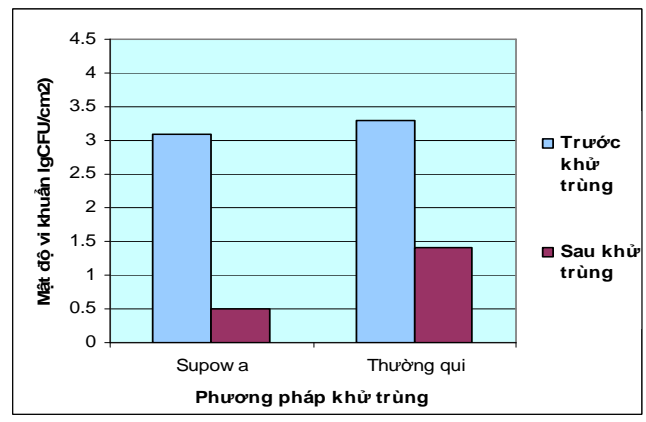

B

Hình 2. So sánh hiệu quả khử khuẩn bằng Supowa và thường quy đối với tổng VKHK (A) và Coliform (B).

Các kết quả trên hình 2 đã cho thấy phương pháp sử dụng dung dịch Supowa cho hiệu quả khử trùng bề mặt bàn inox cao hơn so với phương pháp thường qui. Cụ thể, khi dùng Supowa mật độ VKHK giảm ở mức $3,3 \log _{10} \mathrm{CFU} / \mathrm{cm}^{2}$ so với mức $2,3 \log _{10} \mathrm{CFU} / \mathrm{cm}^{2}$, còn mật độ Coliform có mức giảm tương ứng là $2,6 \log _{10} \mathrm{CFU} / \mathrm{cm}^{2}$ so với $1,9 \log _{10} \mathrm{CFU} / \mathrm{cm}^{2} \mathrm{khi}$ dùng phương pháp thường qui với độ tin cậy $\mathrm{p}<0,05$.

Ở các mẫu trước khử trùng của bề mặt rổ nhựa đã không phát hiện thấy sự có mặt của vi khuẩn E.coli, nhưng đều có mặt 3 loại vi khuẩn: VKHK, Coliform và Staphylococcus. Mật độ vi khuẩn hiếu khí dao động từ $3,0 \log _{10} \mathrm{CFU} / \mathrm{cm}^{2}$ tới xấp xỉ $5,0 \log _{10} \mathrm{CFU} / \mathrm{cm}^{2}$, mật độ Coliform dao động từ $2,0 \log _{10} \mathrm{CFU} / \mathrm{cm}^{2}$ tới xấp xỉ 4,0 $\log _{10} \mathrm{CFU} / \mathrm{cm}^{2}$, còn mật độ Staphylococcus dưới 2,0 $\log _{10} \mathrm{CFU} / \mathrm{cm}^{2}$. Sau khử khuẩn bằng Supowa, mật độ VKHK giảm đi $2,9 \log _{10} \mathrm{CFU} / \mathrm{cm}^{2}$, Coliform giảm $1,8 \log _{10} \mathrm{CFU} / \mathrm{cm}^{2}$, còn Staphylococcus giảm $1,8 \log _{10} \mathrm{CFU} / \mathrm{cm}^{2}$, trong đó có trên $50 \%$ số mẫu không phát hiện thấy vi khuẩn Coliform và Staphylococcus. Các giá trị này lớn hơn đáng kể khi so sánh với các giá trị tương ứng là $1,4 \log _{10} \mathrm{CFU} / \mathrm{cm}^{2}, 1,3 \log _{10} \mathrm{CFU} / \mathrm{cm}^{2}$ và 1,2 $\log _{10} \mathrm{CFU} / \mathrm{cm}^{2}$ khi khử trùng thường qui. Điều này cho thấy, phương pháp sử dụng Supowa hiệu quả hơn phương pháp thường qui khi khử trùng bề mặt rổ nhựa dùng trong chế biến thủy sản $(\mathrm{p}$ $<0,05)$.

\subsection{Hiệu quả khử khuẩn của Supowa đối với bạch tuộc nguyên liệu}

Bạch tuộc nguyên liệu sau khi tập kết về nhà máy đều phải khử khuẩn trước khi được đưa vào nhà máy chế biến để tránh nhiễm khuẩn không mong muốn. Đối tượng này giầu vật chất hữu cơ nên sẽ ảnh hưởng nhiều đến hiệu quả khử khuẩn. Thực tế kết quả phân tích vi sinh các mẫu lấy trước và sau khử trùng bằng Supowa và thường qui đều cho thấy hiệu quả khử khuẩn 
thấp hơn khi khử khuẩn dụng cụ. Mức giảm mật độ vi khuẩn sau khử khuẩn so với trước khử khuẩn đạt xấp xỉ $1 \log _{10} \mathrm{CFU} / \mathrm{g}$, trong đó mức giảm thấp nhất là trường hợp Coliform khử khuẩn thường qui $\left(0,73 \log _{10} \mathrm{CFU} / \mathrm{g}\right)$, còn mức giảm cao nhất là $1,39 \log _{10} \mathrm{CFU} / \mathrm{g}$ đối với vi khuẩn Staphylococcus khi khử trùng bằng Supowa (bảng 1 ).

Bảng 1. So sánh hiệu quả khử trùng bạch tuộc nguyên liệu bằng Supowa và thường quy.

\begin{tabular}{|l|c|c|c|c|c|c|}
\hline \multirow{3}{*}{ Vi khuẩn } & \multicolumn{5}{|c|}{ Mật độ vi khuẩn $\left(\log _{10} \mathrm{CFU} / \mathrm{g}\right)$} \\
\cline { 2 - 7 } & & \multicolumn{2}{|c|}{ Supowa } & \multicolumn{3}{c|}{ Thường quy } \\
\cline { 2 - 7 } & Trước KT & Sau KT & Mức giảm & Trước KT & Sau KT & Mức giảm \\
\hline Tổng VKHK & $6,48 \pm 0,31$ & $5,21 \pm 0,49$ & $1,26 \pm 0,56$ & $6,50 \pm 0,76$ & $5,38 \pm 0,93$ & $1,13 \pm 0,50$ \\
\hline Coliform & $3,56 \pm 0,50$ & $2,72 \pm 0,63$ & $0,85 \pm 0,50$ & $3,87 \pm 0,65$ & $3,04 \pm 0,58$ & $0,73 \pm 0,42$ \\
\hline Staphylococcus & $3,24 \pm 0,47$ & $1,85 \pm 0,57$ & $1,39 \pm 0,44$ & $3,03 \pm 0,47$ & $1,73 \pm 0,57$ & $1,30 \pm 0,44$ \\
\hline
\end{tabular}

Các kết quả trên cho thấy, hiệu quả khử khuẩn bằng Supowa có cao hơn so với khử khuẩn thường qui thể hiện ở mức độ giảm mật độ vi khuẩn sau khử trùng ở cả 3 vi khuẩn được xem xét đều cao hơn. Kết qủa xử lí thống kê các số liệu cho thấy có sự khác biệt nhưng chưa rõ rệt giữa hai phương pháp $(\mathrm{p}>0,05)$. Với hiệu quả khử trùng đạt hiệu suất cao hơn khử trùng thường qui, Supowa đã đáp ứng tốt các yêu cầu khử trùng bạch tuộc nguyên liệu.

\section{KẾT LUẬN}

Dung dịch hoạt hóa điện hóa Supowa đã thể hiện tính năng diệt khuẩn mạnh đối với các vi khuẩn $E$. coli,$S$. aureus, Salmonella và $L$. monocytogenes trong môi trường có thêm chất hữu cơ (peptone $0,1 \%)$. Hiệu lực khử khuẩn của phương pháp sử dụng Supowa tốt hơn phương pháp thường qui $(\mathrm{p}<0,05)$ khi khử trùng các bề mặt bàn inox và rổ nhựa thường tiếp xúc với bán sản phẩm trong chế biến thủy sản . Khi khử khuẩn bạch tuộc nguyên liệu, hiệu lực khử khuẩn của phương pháp sử dụng Supowa tốt hơn phương pháp thường qui nhưng chưa thật sự khác biệt $(\mathrm{p}>0,05)$. Các kết quả này cho phép đề xuất sử dụng Supowa làm chất khử trùng thay thế cho các chất khử trùng truyền thống như $\mathrm{Ca}(\mathrm{OCl})_{2}$ trong chế biến thủy sản.

Lòi cảm ơn. Công trình này được thực hiện với sự tài trợ kinh phí của Đề tài độc lập cấp nhà nước mã số ĐTĐL.2010-T/21.

\section{TÀI LIÊU THAM KHẢO}

1. Mukhina L. B., Duznik N. V., Dmitriyeva Ye., Yu E. B. - Altshul Bactericidal Properties of Neutral Anolyte in relation to Microorganisms Sanitary-Significant for fishing industry, Tuyển tập báo cáo Hội nghị quốc tế lần thứ hai về hoạt hoá điện hoá, Moskva, 1999, tr. 224.

2. Melekhin D. V. - Sử dụng dung dịch ECA trong sản xuất cá đông lạnh, Tuyển tập báo cáo Hội nghị quốc tế lần thứ hai về hoạt hoá điện hoá, Moskva, 1999, tr. 252. 
3. Ozer N. P., and Demirci A. - Electrolyzed oxidizing water treatment for decontamination of raw salmon inoculated with Escherichia coli O157:H7 and Listeria monocytogenes Scott A and response surface modeling, Journal of Food Engineering 72 (2006) 234-241.

4. Huang Y. R., Hsieh H. S., Lin S. Y., Lin S. J., Hung Y. C., and Hwang D. F. - Application of electrolyzed oxidizing water on the reduction of bacterial contamination for seafood, Food control 17 (2006) 987-993.

5. Huang Y. R., Shiau C. Y., Hung Y. C., and Hwang D. F. - Change of hygienic quality and freshness in Tuna treated with electrolyzed oxidizing water and carbon monoxide gas during refrigerated and frozen storage, Journal of Food Science 71 (2006) 127-133.

6. Nguyễn Hoài Châu, Lê Anh Bằng, Ngô Quốc Bưu, Nguyễn Văn Hà, Nguyễn Minh Tuân Nghiên cứu ứng dụng công nghệ hoạt hoá điện hoá để khử trùng nước sản xuất và sản phẩm chế biến thay thế các hoá chất sát trùng trong xí nghiệp chế biến thuỷ sản, Tạp chí Khoa học và Công nghệ 46 (6A) (2008) 89-95.

7. Abdulsudi Issa-Zacharia, Yoshinori Kamitani, Adili Tiisekwa, Kazuo Morita, Koichi Iwasaki - In vitro inactivation of Escherichia coli, Staphylococcus aureus and Salmonella spp. using slightly acidic electrolyzed water, Journal of Bioscience and Bioengineering 110 (3) (2010) 308-313.

8. Abdulsudi Issa-Zacharia, Yoshinori Kamitani, Kazuo Morita, Koichi Iwasaki Sanitization potency of slightly acidic electrolyzed water against pure cultures of Escherichia coli and Staphylococcus aureus, in comparison with that of other food sanitizers, Food Control 21 (2010) 740-745.

9. Sureerat Phuvasate, Yi-Cheng Su - Effects of electrolyzed oxidizing water and ice treatments on reducing histamine-producing bacteria on fish skin and food contact surface, Food Control 21 (2010) 286-291.

10. Susan McCarthy, William Burkhardt - Efficacy of electrolyzed oxidizing water against Listeria monocytogenes and Morganella morganii on conveyor belt and raw fish surfaces, Food Control 24 (2012) 214-219.

11. Nguyễn Hoài Châu, Ngô Quốc Bưu, Nguyễn Văn Hà - Nghiên cứu phát triển và ứng dụng công nghệ hoạt hóa điện hóa ở Việt Nam, Tạp chí Khoa học và Công nghệ 50 (6) (2012) 923-941.

\title{
ABSTRACT \\ INVESTIGATION OF EFFICACY OF SUPER-OXYDIZING SOLUTION IN REDUCING BACTERIA AT A OCTOPUS PROCESSING LINE
}

\author{
Nguyen Van $\mathrm{Ha}^{1,}{ }^{\text {* }}$, Nguyen Hoai Châu ${ }^{1}$, Hoang Van Tu ${ }^{1}$, Nguyen Van Thanh ${ }^{1}$, Trieu Thi My \\ $\mathrm{Hanh}^{2}$ \\ ${ }^{1}$ Institute of Environmental Technology, VAST, 18 Hoang Quoc Viet, Cau Giay, Hanoi \\ ${ }^{2}$ BASEAFOOD Company, Ba Ria, Vung Tau province
}

"Email:ng_vanha@yahoo.com 
Bactericidal strength of electrochemically activated solution "Supowa" (super-

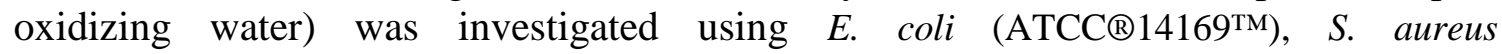
(ATCC®25923 ${ }^{\mathrm{TM}}$ ), Salmonella (ATCC $25241^{\mathrm{TM}}$ ) and L. monocytogenes (ATCC®7644 ${ }^{\mathrm{TM}}$ ) as model bacteria. Bateria in an $0.1 \%$ peptone solution with a concentration of $10^{8} \mathrm{CFU} / \mathrm{ml}$ were completely inactivated after $2 \mathrm{~min}$ exposure with Supowa solution $(50 \mathrm{mg} / \mathrm{l}$ active chlorine). Surface treatment of inoxidable table and plastic basket with Supowa solution resulted in a quite better disinfection efficacy $(\mathrm{p}<0.05)$ compared to the use of conventional disinfectant calcium hypochlorite. Treatment of raw octopus material using Supowa solution showed that its disinfecting efficacy was less manifested and slightly greater than the case of conventional disinfectant $(\mathrm{p}>0.05)$. Supowa solution can be used as a disinfectant for reducing bacteria on contacting surfaces and raw octopus materialsat seafood processing lines.

Keywords: raw octopus, electrochemically activated solution, seafood disinfection, Supowa solution. 